\title{
Germany moves to lower drug prices
}

$\mathrm{T}$ he pricing of pharmaceutical products in Germany is set to undergo its largest change in decades as a result of government legislation that brings free pricing to an end in a bid to contain spiralling drug costs.

Currently, Germany is one of the only countries in the world, in which pharmaceutical companies can freely set the prices for their products. But as of Jan. 1, 2011, a new system for determining drug prices will be adopted as a result of The Act for the Restructuring of the Pharmaceutical Market, which was passed by the upper house of the German parliament in November 2010.

Under the new legislation, drug companies will still be able to freely set a price for a new drug, but it will only apply during the first twelve months of the drug's introduction on the market. During that time, the companies have to prove that the drug provides some form of added clinical benefit compared to existing drugs or it will be included in a reference-pricing scheme. (There are national variations in reference-pricing systems but typically, a "reference" drug is chosen from within a group of drugs that are considered to be equally effective and safe. The price for that reference drug is covered and basically, those who want a more expensive drug are obliged to pay the difference).

The German coalition government hopes the reforms will yield a significant reduction in the $€ 32$ billion spent on medicines last year by the nation's statutory health insurance system. A $16 \%$ rollback on prices and a three-year price freeze have already been introduced. The government estimates the latter measures will save $€ 1.2$ billion annually.

The new pricing scheme will likely have an impact on many countries, Canada among them. "Germany's role as a key reference market will contribute to spread downward pressure on prices to 18 countries [as well as Canada] using Germany as a reference to set their price," writes Anne-Charlotte

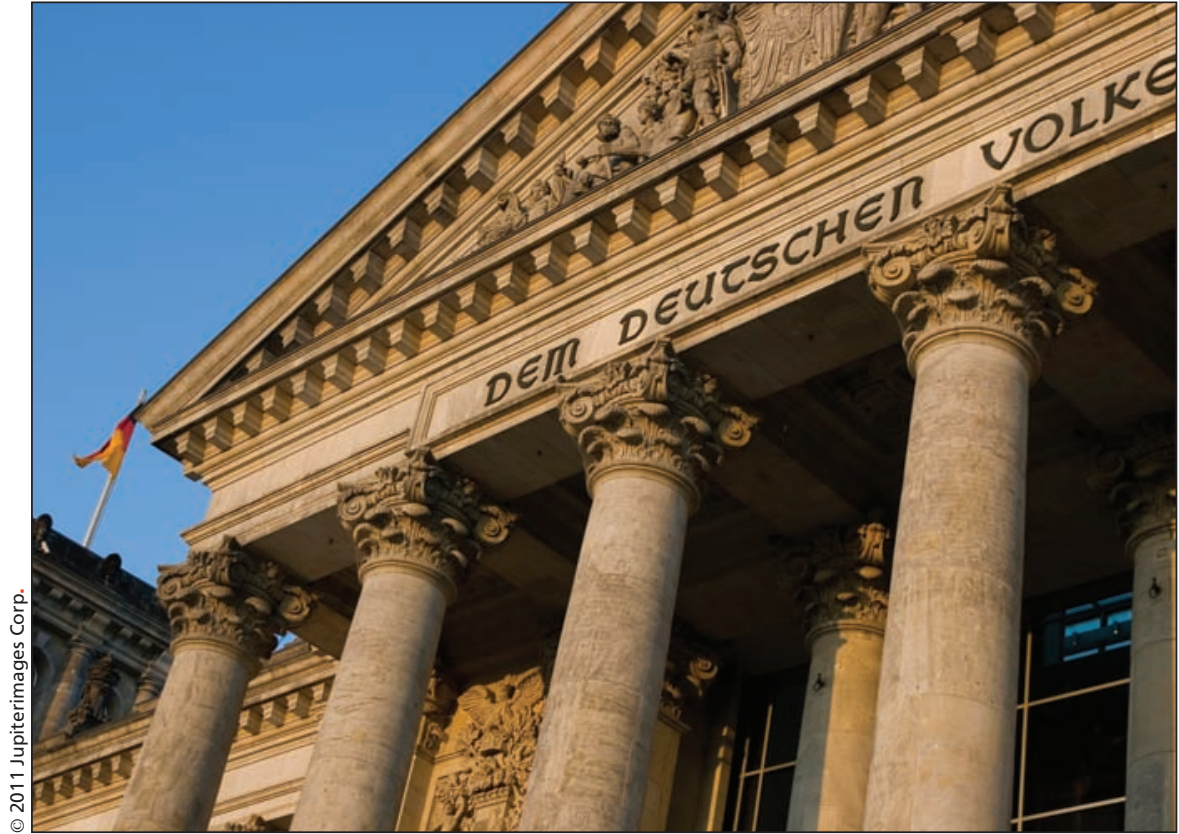

The German coalition government hopes the reforms will yield a significant reduction in the $€ 32$ billion spent on medicines in $\mathbf{2 0 0 9}$ by the nation's statutory health insurance system.

Honor, health care analyst at IHS Global Insight in an email. Those 18 countries are Austria, Belgium, Finland, France, Greece, Hungary, Ireland, Israel, Italy, Japan, Luxembourg, Netherlands, Norway, Slovakia, Slovenia, South Korea, Switzerland and Taiwan.

While some are calling it the end of pharma paradise in Germany, it is still far from clear exactly how large of an impact the legislation will have. The price for drugs which demonstrate an added benefit will be set through negotiations between health insurers and companies. If they are unable to reach an agreement, an arbitration board will set the price.

"We will have to see, whether that really leads to savings of $€ 2$ billion," writes Ann Marini, spokesperson for the federation of statutory health insurers, GKV Spitzenverband, in an email.

Marini stresses that the negotiations between insurers and companies won't be about price but rollbacks on price.

German reference prices will still be freely set by pharma companies, she writes. "It is therefore likely, that the knock-on effect on prices in other European countries will be very small."

In fact, some observers cautioned that the new model could actually lead to inflated prices, with pharmaceutical companies setting the initial price higher to make more money in the first year and lay the groundwork for subsequent negotiations that start at a higher level than might otherwise have been the case.

"We will only know, what happens, when the law has been put into practice," says Jürgen Windeler, head of the Institute for Quality and Efficiency in Health Care in Cologne, Germany, which was established by the government in 2004 to produce evidence-based reports on drugs, surgical procedures, diagnostics and treatment guidelines.

The German Association of Research-based Pharmaceutical Companies echoes the sentiment. "This is not a rebate but a very dynamic system and it's impossible to know its exact effects in advance," says spokesman Jochen Stemmler. 
It is also unclear how many drugs will actually have their prices negotiated.

Under the new regulations, the Institute for Quality and Efficiency in Health Care will be called upon to evaluate company claims about a new drug's added benefit. But the criteria for making that determination will be set by the ministry of health, limiting the independence of the institute.
And some changes in the law will make it harder to reach a negative verdict. "If evidence of a clinical benefit is lacking because the relevant studies have not been done, that will not be enough," Windeler says. "It will only be possible to instruct pharma companies to produce that evidence in new studies."

This could mean that fewer drugs than anticipated will be forced into the pricing scheme. Still, Windeler believes the reforms are a step in the right direction. "It creates an incentive for real innovation" and will result in such benefits as a public database for all clinical trials, he says. "This law is certainly better than no law at all." - Kai Kupferschmidt, Berlin, Germany

CMAJ 2011. DOI:10.1503/cmaj.109-3759 